\title{
Law-Political Philosophy in Plato's Laws as a Suggestion for Transformation of the Contemporary Political Reality
}

\author{
Christos Terezis \\ Lydia Petridou \\ University of Patras, GR
}

TEREZIS, CH. - PETRIDOU, L.: Law - Political Philosophy in Plato's Laws as a Suggestion for Transformation of the Contemporary Political Reality.

Philosophica Critica, vol. 2, 2016, no. 2, ISSN 1339-8970, pp. 19-31.

In this study, focusing our attention on Plato's Laws, we attempt to present how his political philosophy is capable of becoming a suggestion for transformation of the contemporary political reality. In order to bring to the light the utilizable views, we approach very carefully the concept of law, examining the conditions under which it is considered to be a science, its relation to ethics, its specifications, its importance in a customary level and the way in which it is related to the political system. We also discuss the content of the laws and the particularly important role of the legislator. The most interesting platonic views emerge to be the dialectic relation between personhood and collectivity, the determination of the political system by moral values, the utilization of the laws for spiritual transformation of the citizens and the need for unchangedable principles as foundations of the legal system.

Key words: Plato - Laws - Political philosophy - Law - Ethics

\section{Introduction}

The issues related to law were of major importance for the ancient Greek world, actually since the Homeric and the Hesiodic philological tradition. They were associated not only with the way in which the society and its politicalinstitutional structure were established and function, but also with cosmological questions, researches and interpretations, under a systematic reading perspective. The second version was dominant in the Pre-Socratic tradition, because of its special scientific questions, the theoretical premises of which were still 
preserving anthropomorphic models or models of social structure. The subjective spirit had not been yet distinguished from the objective reality; holism was a fact. Either way, law was considered to be the qualitative power that kept the balance, aiming always at something better, or providing for the dialectical exceedance between opposing forces. Possessing somehow the power and the function of a natural law it was also ensuring social harmony either through discussion and exchange of opinions or through regulation. This was a natural regulatory basis, with the possibility to intervene in every case of deviation from balance or harmony. Therefore, its ontological foundations were taken for granted, despite the fact that in most cases they were described in a narrative-fictional way. Subsequently, if not initially, law was considered in theological perspective, with the rational elements to be found all over because of the structurally regulatory content with which it had been surrounded; furthermore, these rational elements raised demands for precision. What will follow, we believe, might provide a reading area for suggestions for transformation of the contemporary political reality.

\section{A) Law in Plato's political texts}

The concept of law is one of Plato's most favorite issues. He deals with it in many dialogues, but mainly and systematically in Gorgias, Republic, Politicus and actually in many respects, both thematic and methodological. The common ground, however, of all his perspectives shows that law itself represents (essential element) as well as ad extra ensures (functional element) harmony, in terms depending on the meaning, importance, necessity or prospect anytime they are actually raised. In these terms, however, there is nothing typical and ordinary; furthermore, there is no strategy to accomplish any corporatist interests. Whether he refers to major political issues or to minor procedural matters, a rule is required, which both by definition and because of the current conditions had to be activated and become practically accepted, since it is believed - and oftentimes in an axiomatic way - that this rule is necessary and universal regarding the good function of the society. This generalized regularity means that it necessarily pushes us - in the sense of a stereotypical but not inflexible inclusion - to a rational choice of ways of dealing with problems occasionally presented; note that these problems are developed mainly due to either people's lack of education or pathogenic competitions in a society (other time it could also lead to interpretative disorientations). In other words: law, by projecting its ability for regulation in the form of somewhat leading and autonomous principle universally based on its own foundations. The principle is also validated by its qualitative products it is believed to cause and it imposes specific restrictions to its 
recipients, which, only if people accept them consciously and really understand them, deserve to be considered as such factors.

The dialogue however in which Plato makes a really systematic approach of the law is Laws, the last - or at least one of the last - chronologically speaking work, which, since it belongs to the top of his philosophical concerns, is the most important objective criterion to get in touch with his final position on this issue ${ }^{1}$. In this study we will attempt to find - besides a number of other issues which are included in the broad sense into the political planning - mainly how the Athenian thinker structures a scientific and philosophical approach on law in the abovementioned, and actually extensive and methodologically cohesive, treatise of his. We have to mention in this early stage of our analysis that his approach is holistic and that it connects law, as a functioning part of the practical Reason, with the various philosophical fields; among them the leading position holds metaphysics, as well as theology2. The way in which the founder of Academy structures his treatise is systematic and functional and is subject to the following general theoretical schemes, which we will briefly present next, having the subtractive processes on all of this Platonic work as its basis. So, the order in which these subchapters are structured, results from the reconstructions that we choose, in order to accurately capture the system of the political thought that Plato attempts to establish.

\section{B) Law in Plato's Laws}

\section{B1. The science of law}

The science of law is the systematic structured theoretical-research field, which deals with the construction of the necessary, regarding the aims and their independence from the consequences of their direct implementation, and with the conceptual material that will lead through its strict epistemological definitions

\footnotetext{
1 Whether in this dialogue Plato presents his own practical political proposals or says what Socrates would have said, see the very interesting study of (Zuckert 2004, 374-395).

2 On the theological foundation of law and the position that man-legislator holds in such a theocentric context, very interesting is the following comment of (Brès 1973, 334): “Maintenant il n'est plus question d'homme d'Etat idéal et l'homme d'État réel ne peut être qu'inférieur à la loi. Mais il en va tout autrement du législateur. Ce lui-ci n'est pas l'homme d'Etat, il est exalté, situé au niveau le plus élevé qui est celui-là même de la loi." Cf. (Luccioni 1958, 214), where we read: "La cité platonicienne se constitue avec le souci constant, qui anime son auteur, de ne pas oublier la divinité et de tenir le plus grand compte possible des indications qu'elle a pu donner et de se conformer aux principes qu’on peut considérer comme l'émanation de sa volonté générale."
} 
successively or on the basis of an internal dialectic structure to the following: understanding the deep meaning of the law, finding the conditions that bring it to the light and establish it, and detection of the mission that it has undertaken during the development and the change of the society, regarding both a legal and ethically established law level and a meta-law level. I.e. it belongs to its responsibility to find the reason why a collective entity of political and legal function - subsequently not of an archaic texture - arises, as well as the possibility of a purpose - or even of an entelechy - that it represents, in its own terms. Afterwards, this presence will be examined according to the criteria that are set by a trans-historically confirmed objective measure. This field, which is included into the fundamental issues of the legal interpretation, has been systematically approached since the Greek classical antiquity. At a time during which the political action is defined as the essence of the anthropological, ethical and social question, it is inevitable, on the one hand, that issues related broadly to the public administration and causing collective discussions get the most attention and, that the terms of success be searched on the other. Here, it is believed that the administrative organizations function not only helpfully, but also in order to use rules that are not subjected to relativism. This is dialectics of great demands. What is considered to have acquired claims of universality is invited to confront every occurring particular, which actually sets resistances and challenges.

Despite its otherwise important function, the science of law is not a strictly limited and independent field, but is included in the general matters of ethics, politics and metaphysics that the ancient Greek world sets. Thus, it also deserves a meta-reading. This combination is not due to a theoretical impossibility for specifications, but results from the holistic and not through autonomy-oriented or divisive way the Greek thought used to deal with issues then. In such a composite framework of mutual reductions, the theoretical fields are approached mainly - if not exclusively - during their functional relevance, rather than through their distinct terms, which, however, are clarified and specified further and further. We have to mention that these specifications make the communication obvious. We find this perspective in the Platonic Laws, where the law does not get an autonomous conceptual definition, but is combined with number of areas related both to theory and action, which in the context of a mutual feedback also allow reflective questions. The aim is the reconstruction of the terms in which a specific political system will be established. On one condition: the functions of the above-mentioned areas are checked according to the factual data and the rationality regarding their ability to implement functionally into other areas. The adopted model makes everything exist in everything, each case in its 
special way. Thus, both, the values will be extended and new ways for capturing the common rule, which is considered to be most important, will arise. ${ }^{3}$

\section{B2. The relation between law and ethics}

The most important issue that Plato examines in Laws and which he considers extremely important for anthropology and political eschatology is the relation and the distinction between law and ethics, two leading ways in which the individual and the communicative activity appears, which are included -more or less - into a broader political context, not necessarily a univocally secularized one. Their meeting constitutes a delicate balance, since ethics is primarily defined by irremovable a priori bases, principles or acceptances, which come up together, regardless of their subsequent appearances or inclusions, through their individual duty, even if this has not yet become conscious. Oftentimes, ethos is defined by a usual criterion, which is axiomatically considered to be a positive thing and therefore should be followed. Law mainly arises from the collective activities of already formed political subjects, those under formation or even political formations with legislative and judicial bodies defined according to the specific circumstances of each historical period. At this point, a systematical questioning emerges, since we are looking for the mutuality between two universal concepts, regardless of what is going on every time and regardless of the relativism on which it depends. The specific, however, historical conditions are of major importance, since in the sense of a special culture they are also the reason why this relation appears in special ways in time and space. They also explain its absence or its deficits. Through the examination of the individual cases, we find that the law and the ethics vary - theoretically, valuatively and interpretatively depending on the space-time data of the cultural environment in which they emerge and which they express.

Inevitably, the following question arises: taking into account they are confirmed and compulsory for the variety of theories, is it possible to find common grounds in these two concepts; moreover, is it possible to let universally applicable ethical-law rules emerge through their interpretative application? Plato preserves here also the theory of last regulative archetypes and their unity, despite the variety and the historicity of their applications, their immanent and applied character. He is from now on interested in how through the specialized nominalism of the findings he will reach universal schemes of integrities. Even the most unsuspicious reader would realize that during the reasoning-dialectical unfolding of the Laws, law and ethics are mutually related in the sense of a com-

${ }^{3}$ Plato discusses these positions mainly in the ninth book of Laws. 
plementarity and are included in the same categorical framework, while at the same time they present original subsets of a larger unity, which results from the combination of Metaphysics with Politics. Of course, the first field is considered to be ontologically and axiologically primary, but the one that is going to function in a transcendent way over the superficial is secondary. Furthermore: law and ethics are identical as to their reasonably intended aims and they function according to strict regularities of rationality, which permanently have a prescriptive - and, in a next level, teleological - power with respect to their recipients. Thus, throughout the whole "journey" and unless the teleology is accomplished, they function according to a semantic perspective, which is changeable by time. ${ }^{4}$

\section{B3. Specializations of the law}

Regarding the systematic autonomy of those being expressed - basically here we are speaking about a theoretical construct, not necessarily ontologically existent at least concerning the sequential order that we are going to suggest - although methodologically necessary and not arbitrary as to its construction. We would say that it appears in Laws law in the following hierarchically axiological sequence: a) metaphysical law b) rational law c) positive law. This structure follows specific empirical historical criteria - e.g. the cultural succession of the societies and the periods -, from which maybe it takes some of its motives. It deserves, however, attention that this distinction is not necessarily conscious in the wider population, which in the archaic period of time functions, more or less, according to customs, the typical repeatability and with skepticism regarding radicalism. Why Plato points out or uses here and there - i.e. without the expected systematicity - the scheme, is a matter connected to his intention to ensure the interpretative keys for understanding the history process, which has the "advantage" to continue. His attitude is moderately critical, with the intention to fix pathogeneses. In his thought, human society is subject to adventures, which have been caused by its ambiguities or contradictions. The Athenian philosopher realizes the social problem in terms of historical failure, i.e. in terms of weakness of the current cultural constructs supposed to offer to the human actions a worthless vision of life, when specified with respect to axis of general purpose.

The most important is to find the appropriate solution, which will show a way out of the already existent or out of emerging problems of each society. It would be reasonable to seek the answers in a world superior to the world of the sensible - which has proved that it does not possess the methodological tools or what in

${ }^{4}$ We find these platonic views mainly in the fifth book of Laws. 
general is needed to self-adjust as it has to; and note that these answers, after being found, have to be applied according to the circumstances. The second condition is necessary, so that rationality, or reasonability, which grounds the established regulatory rules, appears and actualizes itself, in order not to unilaterally reduce to the area of an unspecified metaphysical idealism or to an imaginary utopia. So, crucial questions related to the political matter arise, which, also through the solutions offered by the conceptual categories, become currently relevant in deciding what should be done or applied. The selected realistic criterion looks for extended validations. More specifically, it is perfectly acceptable that the superior regulatory principles of the metaphysical world possess ontological foundations and that they constitute, regardless of whether they are accepted or not, the entire legitimizing criterion and the permanent regulatory power for what takes place in the social body, as the political, regulatory and executive activities. It is therefore believed that these elements, which represent the authenticity of the metaphysical law, have to develop through human initiatives, in order to structure in a state level or to clarify the intellectual and the structural conditions. Thus, the positive law occurs as an advanced development of the customary law - as we are going to explain below, of a construct of the historical, cultural and social uncertainty - and becomes valid, since it reflects the anthropological and historical change of the metaphysical archetypes in a law framework and in acting institutional persons. The presence of such persons, a decisive factor for the establishment of the new law tendencies, introduces now individuality - and actually one that takes initiatives and possesses the necessary and acknowledged level of education - and brings to the light the new era of enlightenment, which no longer desires typical repetitions or reproductions.

However, since the problems of the social or political pathogenicity - as an extension of the anthropological and the ethical one - are permanently a possibility, require careful therapeutic interventions; and such a special attention is provided mainly by the rationality in which we face the facts. This is a quality that ethically is included into the positive law, as an internal regularity from which it takes reasons, power and meaning while it self-adjusts according to the circumstances. This kind of self-adjustment is necessary, since the matter no longer belongs to self-sufficiency, unchangeability and absoluteness of the metaphysical world, but has been included into the processes of historical becoming, which topically actualizes the universal through new reconstructions.

We may also say - and not only for methodological reasons - that we are speaking about an autonomous law regarding the positive law, which is formed by the superior powers of the human consciousness following the way they themselves have fruitfully - and with the awareness of the ameliorative interventions every period of time has to accept - assimilated the metaphysical archetypes. This emphasized reception signifies the following gradually unfolding 
transformation: human consciousness turns these archetypes into regularity, regardless of whether the empirical foundations or validations are directly and steadily secured. This is a permanent arrangement, which leads to the conclusion that metaphysics holds an authentic legitimacy, expecting its own institutional legitimacy. Positive law accomplishes this purpose, protecting itself this way both through its usage compared with the rational law and through the fact that it is a mandatory factor - against subordination to the effects of the social deviation and political relegation or from the circumstances raised by the individual and corporate expediencies. Therefore, society changes into the state of law, when it forms its legal system in accordance with a plan based on an authentic ethical duty which is metaphysically founded on collective principles and not on selfish strategies of subjective interests. In Platonic view, a state of law does not function as a compromising balance factor between two conflicting powers, it rather ethically defines its mission as a lesson for virtue, with in each case legal and appropriate intervention, with institutional and not authoritarian power ${ }^{5}$, or by structuring what has to be done in each case one understands how exactly it should function. The final purpose of this lesson is the recovery of all the divine regulatory archetypes and the transformation accomplished through its topical activation of the sensible reality. Therefore, positive law is specialized through laws, each of which - as a content, structure and application - constitutes a reflection of the way in which the politically organized society guided by rationality translates the divine archetypes into action and reconstructive prospect. It is the time when the constitution of a state is established and the laws that will apply it when necessary or transform it in various ways into eurhythmy are passed. ${ }^{6}$

\section{B4. Customary law}

In order to broadly define the relation between laws and ethics in Laws, it is necessary to take into account that Plato refers to customs, in which he pays great attention to the establishment of laws. This is an issue to be examined both historically and systematically, two fields that are extensively determined by psychological conditions of the unconscious mind. A custom, therefore, reflects an indefinite social life, without clear conceptual distinctions, with a confused sense

\footnotetext{
5 And it should be noted, that generally virtue is treated by Plato holistically, with wisdom, however, sometimes being one of the various virtues and sometimes constituting the whole of virtue. The dialogues Laches and Protagoras are particularly interesting on this. On this issue, see also (Devereux 1992, 765-789).

6 These are views that are mainly found in the tenth and eleventh book of Plato's Laws.
} 
of ethical duty and with relation regarding the supernatural world forced or directed by indecisions. We are speaking about deficiencies that mainly describe a tribal society, which has not been yet organized institutionally. In its formulation various elements participate, oftentimes without any mutual relations, such as the superstitious relationship with God, the social pressures and the risk of incompatibilities it may cause, or various intentions accompanied by an attitude of repayments. In relation to custom, ethos and law are not yet actualized advanced cultural state, in the context of which human political - and not only the social - nature will be consciously activated. As we have seen, these values are found in politics, they determine the quality and the time of the actions and provide a dialectically and reflectively consensual dimension to the communication between individuals as citizens. Through their political appearance, they bring to the surface individual rights and establish them legally-institutionally. In Plato's work, these two factors co-constitute the unity of the political life, which, by capturing the metaphysically founded good and by participating in the metaphysical perspective of bliss, actualizes the leading anthropological values and defines teleology of high standards. These are the transitions that constitute the liberating adjustments and the self-adjustments of the Enlightenment. However, customs function as a critical preparation for the above and through their repetition or through their effects they cause broader concerns. ${ }^{7}$

\section{B5. Law and political system}

From the political point of view, we would say that Plato supports a mixed political system, in which monarchy and democracy coexist or meet in such a way, so as to be mutually complementary regarding their positive elements and mutually neutralized and deterrent regarding the domination of the one over the other. Their purpose is to ensure the balance of institutional powers and administrative functions. Thus, in some cases he suggests with great insistence, a division of the authorities as to their responsibilities. Each would correspond to a specific political organization of the social life and would bring its quality to the light. Thus, he combines with great balance the expertise in leadership with the actual freedom, so that both the stability of the system be permanently ensured and the individual rights be promoted as political values, which guarantee an increasingly expanding cultural acquis ${ }^{8}$. Note also that Plato seeks symmetry and harmony between the two, at first divergent, perceptions and practices on life,

\footnotetext{
7 Plato discusses these matters mainly in the first and third book of Laws.

8 On the concept of freedom in Plato and, especially, in Laws, see (Stalley 1998, 145-158). Cf. (Bobonich 1991, 365-388). These two studies clearly show the difference between Plato in Republic and Politicus and Laws.
} 
since he intends to raise them in a third state, which would constitute their composition. He does not intend to compromise their strategies ensuring their power individually. We could further say that the separation of powers into legislative-executive-judicial may cause malfunctions in the unity of a state, which, for the philosopher, is the final and greatest political goal. Since, however, he is a theoretical analyst, he puts them into the same political base aiming at the same transcendental - compared with the stagnation - institutional effect. Note that each one of them follows special methodological legal processes. Thus, through the chosen institutional model he ensures unity. Now, unity prevents the citizens or the corporate groups from making laws individually. At the same time, he does not hold down the inspiration or the choices of the citizens. This is the point where the necessity of the presence of a legislator arises. The person who represents this institutional factor constitutes the area in which the individual forms of power dialectically meet, while each one of them admittedly keeps its individuality. Actually, according to Plato, the constitution of legislative system requires a high-level mental ability, in order to offer - and to contribute - to the composition of a rational political scheme for improving the social body. Moreover, the above-mentioned scheme ensures this transformation via permanent rethinking, both as to the terms that topically promote the political processes and to its intended prospects. The legislator represents the consciousness and the qualitative structural perspective of a state, he is the spirit that includes its concerns, expresses its rationality and promotes its intention towards what one may consider as mental and practical goods. He is, therefore, the factor of a high moral teleology. ${ }^{9}$

\section{B6. The content of the laws}

Plato seems to consider also very important the content of the laws, the purpose of which lies in the transformation of the political life into its increasingly mature forms, not only as far as the institutional character is concerned but also regarding how citizens will change from neutral subjects into a living expression of the laws. ${ }^{10} \mathrm{~A}$ purpose however is not achieved without the necessary tools, a parameter which leads him to support the conviction that laws have to be substantially structured, so as to ensure logical consistency, order and organic succession. A case by case law or a law which is composed of compromises does

\footnotetext{
9 Plato discusses these views in the third and fourth book of Laws.

10 Thus, law in Laws becomes the fundamental rule which replaces the principle of the rule of the wisest, which Plato proposed in Republic. On this issue, see (Cohen 1993, 301-317). See also (Morrow 1941, 105-126).
} 
not belong to his interests, which consist in how the rationality will replace the historical ambiguities. Of course a law responds to a current need, the presence of which makes the law actually necessary; law, on the other hand, has to interpret and to resolve the very need itself. At the same time, however, law defines its responsibilities for achieving specific purposes according to the supreme regulatory principles having been set by the state. Of course, Plato speaks about a state which expresses spirituality in a specific way.

Thus, the specification of the laws during their constitution and their applicable projection must not lead laws to contradictions, which drag citizens into misty uncertainty regarding the function and meaning of the public life. Laws have to represent an interpretation of collectivity. The issue that concerns the application of laws is also one of a main political interest. It is a subject present not only to current procedural matters, but also to the general institutional logic of dealing with offences; the purpose is to ensure moral virtues. This is where realism of the timeliness meets idealism of the prospect, with transforming power of ethics being the decisive criterion. The law analyzes, explains and interprets everything one encounters in terms of the social body taken as a fact, as a substrate for many choices and as an extension to the general cultural scene. For its sake it determines the institutional approach that fits to it, in order to express itself according to these data. For instance, giving someone a sentence results from a complex judicial process, during which the offence is considered in a pure sense and in the light of the course of its implication; the reason why it happened is also searched. I.e. it confirms a social counterexample and, through the opposition between rationality and reality or through the transformative possibility that the first has over the second, it exemplifies a virtuous paradigm.

Furthermore, from the positive point of view, law permanently expands in a structural way towards the social body and in compliance with the developing political planning, provided that it corresponds to the main purpose of what is right. This planning has to create, from its point as well, a rationally structured just-political scheme. Moreover, it would never be actualized if the individual cases would not be examined carefully and in detail; we are actually speaking about a combination of realism with idealism. For the political body, legislation is actually a necessity. It captures the problems, which occurred because of its internal contradictions or by external factors and attempts to cure them, to stop them from happening in the future again. Law not only intervenes in a restricting or arresting way but it also works as a lighting of consciousness, and not only through the choices-behaviors-acts that it suggests but also through the reasoning in which it establishes them as functioning factors of the intellectual reform of the political subjects. It shows how society, through specific law criteria, will reach its self-consciousness in an enlightening context, in which the moral 
foundations will be transformed into political effects that would be able to make the current processes go better ${ }^{11}$.

\section{Further discussion}

What we have discussed in the present study, may constitute a sufficiently effective suggestion for transformation of the political systems and the social relations that have been formed in modern times. The aspects offered for utilization are the following:

1. Plato proposes a dialectic relation between personhood and collectivity, through which, on the one side, he shows that the two terms are complementary and, on the other, he ensures the necessary for both the individual and the social development balance.

2. Regarding the political system, he suggests not to fall under economy, but to be determined by moral values. In this way, he actually liberates man from externally imposed chains.

3. As for the laws, he believes that they should not be imposed in a mandatory way to citizens, but they have to be used for their spiritual transformation. I.e. he regards them as a way for qualitative development.

4. Finally, he seeks to establish unchangeable principles that will provide foundations for the legal system in such a way so as not to fall under corporatist interests and forces of implicit social control.

\section{References}

BOBONICH, CH. (1991): Persuasion, Compulsion and Freedom in Plato's Laws. In: Classical Quarterly, 41, 365-388.

BRÈS, Y. (1973): La Psychologie de Platon. Paris: P.U.F.

COHEN, D. (1993): Law, Autonomy, and Political Community in Plato's Laws. In: Classical Philology, 88 (4), 301-317. See also MORROW, G. (1941): Plato and the Rule of Law. In: Philosophical Review, 50, 105-126.

DEVEREUX, D. T. (1992): The Unity of the Virtues in Plato's Protagoras and Laches. In: The Philosophical Review, 101 (4), 765-789.

LUCCIONI, J. (1958): La pensée politique de Platon. Paris: P.U.F.,

STALLEY, R. F. (1998): Plato's Doctrine of Freedom. In: Mathew Soteriou (ed.):

Proceedings of the Aristotelian Society, 98. London: Wiley, 145-158.

11 These are views that are discussed mainly in the sixth, seventh and twelfth book of Laws. 
ZUCKERT, C. H. (2004): Plato's Laws: Postlude or Prelude to Socratic Political Philosophy? In: The Journal of Politics, 66 (2), 374-395.

\section{Christos Terezis}

University of Patras

Faculty of Humanities and Social Sciences

Department of Philosophy

GR26500, Rion, Patras

Greece

terezis@upatras.gr

\section{Lydia Petridou}

Postdoctoral Researcher

University of Patras

Faculty of Humanities and Social Sciences

Department of Philosophy

GR26500, Rion, Patras

Greece

petridoulydia@yahoo.gr 